\title{
Fast upsetting of circular cylinders of aluminium metal matrix composites: experimental results and numerical analysis
}

\begin{abstract}
Cylindrical specimens of $\mathrm{Al} / \mathrm{Cu}$ and $\mathrm{Al} / \mathrm{Li}$ metal matrix composite (MMC) were subjected to dynamic compression at room temperature using an experimental drop hammer. Force-time and displacement-time traces were recorded. The experimental results are compared with theoretical results obtained using finite-difference analysis proposed in a previous paper by the authors [1]. The computational results obtained for the force-time histories agree reasonably with the experimental observation. Effect of strain rate and thermal softening on the mechanical behaviour of $\mathrm{Al} / \mathrm{Cu} \mathrm{MMC}$ and $\mathrm{Al} / \mathrm{Li} \mathrm{MMC}$ were examined.
\end{abstract}

Keyword: Metal matrix composites; Strain rate; Dynamics behaviour; Finite-difference numerical technique 